\title{
URGENSI SENI RUPA KALIGRAFI DALAM PENDIDIKAN ISLAM
}

\author{
Nurul Hidayah Puji Lestari ${ }^{1}$, Yazida Ichsan ${ }^{2}$, Rachmat Sukriyanto ${ }^{3}$, Saas Asela ${ }^{4}$ \\ Universitas Ahmad Dahlan \\ nurul1800331028@webmail.uad.ac.id,yazida.ichsan@pai.uad.ac.id
}

\begin{abstract}
Islamic Religious Education aims to form the Islamic personality of students in accordance with Islamic law who believes and upholds monotheism.Many methods in learning can be used to help educators achieve the goals of education, but rarely use works of art or practice using these works of art in terms of learning Islamic religious education, one of which is the art of calligraphy Calligraphy art is included in the fine art of writing beautifully where the writing is adjusted to predetermined rules. In addition, of course, it has also been explained what the laws of this art are in Islamic law. But what if this art is used for The learning process for the realization of the goals of education will be discussed in this article. This study uses the literature review method, with the aim of describing the urgency of the art of calligraphy in learning Islamic education. This aligraphy can help the learning process of Islamic Religious Education to form Islamic characters in accordance with Islamic law.
\end{abstract}

Keywords: Art, Calligraphy, Islamic Religious Education

\begin{abstract}
Abstrak : Pendidikan Agama Islam bertujuan untuk membentuk pribadi Islami peserta didik sesuai dengan syariat Islam yang beriman dan menjunjung tinggi ketauhidan. Banyak metode dalam pembelajaran dapat digunakan untuk membantu pendidik mencapai tujuan dari pendidikan, namun jarang yang menggunakan hasil karya seni atau praktik menggunakan karya seni tersebut. Dalam hal pembelajaran pendidikan Agama Islam, salah satunya yaitu seni rupa kaligrafi. Seni kaligrafi termasuk dalam seni rupa menulis indah dimana penulisannya disesuaikan dengan kaidah yang telah ditentukan. Selain itu, tentu telah dijelaskan pula seperti apa hukum dari seni rupa ini dalam syariat Islam. Namun bagaimana apabila seni ini digunakan untuk proses pembelajaran demi terwujudnya tujuan dari pendidikan akan dibahas dalam artikel ini. Penelitian ini menggunakan metode kajian kepustakaan, dengan tujuan memaparkan urgensi dari seni kaligrafi dalam pembelajaran Pendidikan Islam. Dari hasil kajian kepustakaan tersebut didapatkan bahwa seni kaligrafi ini dapat membantu proses pembelajaran Pendidikan Agama Islam untuk membentuk karakter Islami sesuai dengan syariat Islam.
\end{abstract}

Kata Kunci : Seni, Kaligrafi, Pendidikan Agama Islam 


\section{PENDAHULUAN}

Pengertian Pendidikan dalam Undang-Undang Sistem Pendidikan Nasional (UU Sisdiknas) No.20 Tahun 2003 Bab I Pasal I menggariskan bahwa : "Pendidikan adalah usaha sadar dan terancana untuk mewujudkan suasana belajar dan proses pembelajaran agar peserta didik secara aktif mengembangkan potensi dirinya untuk memiliki kekuatan spiritual, keagamaan, pengendalian diri, kepribadian, kecerdasan, akhlak mulia, serta keterampilan yang diperlukan dirinya, masyarakat, bangsa, dan negara. Dari pengertian ini dapat kita ketahui bahwa pendidikan adalah usaha yang telah direncanakan untuk menciptakan proses pembelajaran untuk mengembangkan potensi peserta didik. Harapannya dari proses pembelajaran ini menghasilkan insan yang berkualitas, memiliki kekuatan spiritual, cerdas, berakhlak mulia, dan life skill. Maka jelaslah bahwa upaya pendidikan dilaksanakan melalui jalur yang disebut satuan pendidikan sekolah dan diluar sekolah. ${ }^{1}$

Seni adalah aktivitas yang mengekspresikan pengalaman hidup dan kesadaran artistik. $^{2}$ Dalam bahasa Indonesia, salah satu arti dari seni adalah halus, sedangkan dalam artian lainnya ialah kecil atau indah. Dari kata seni inilah terbentuk kata kesenian yang berarti keterampilan indah. Jika dikajii lebih jauh, definisi seni dan kesenian itu berhubungan dengan keindahan dan kenikmatan. ${ }^{3}$

Seni, diungkapkan dengan istilah apapun, suatu karya seni dimaksudkan untuk 'memberi makan' kebutuhan manusia akan rasa di sekitar keindahan. ${ }^{4}$ Namun dalam konteks sosial budaya tertentu, seni lebih cenderung ke kebutuhan yang lebih menjurus kepada sensasi untuk mendapatkan hal-hal yang aneh dan tidak biasa bahkan cenderung vulgar. Oleh karenanya terkadang seni lebih dianggap sebagai sesuatu hal yang berbau bebas dan vulgar. Terutama bagi sebagian banyak penduduk Indonesia, menganggap bahwa seni ini telah melenceng jauh dari ajaran agamanya ataupun pendidikan agama sehingga tidak begitu mendapat dukungan bahkan dianggap kurang tepat untuk media belajar.

\footnotetext{
${ }^{1}$ Syafril and Zelhendri Zen, Dasar-Dasar Ilmu Pendidikan (Depok: Kencana, 2017), 32.

${ }^{2}$ Yani Mulyani and Juliska Gracina, Kemampuan Fisik, Seni, Dan Manajemen Diri (Jakarta: Kelompok Gramedia, 2007), 30.

${ }^{3}$ Dedi Nurhadiat, Pendidikan Seni Rupa (Jakarta: Grasindo, 2004), 2.

${ }^{4}$ Jim Supangkat and Rizki A Zaelani, Ikatan Silang Budaya; Seni Serat Biranul Anas (Art Fabrics, 2006), xi.
} 
Berbicara mengenai pendidikan agama dan sistem seni memanglah menarik dikarenakan keduanya memiliki hubungan yang sangat erat. Apalagi banyak banyak dikalangan ulama yang memeperdebatkan seni dengan agama dengan berbagai pandangan masing-masing. Akan tetapi islam mengajarkan untuk mengembangkan seni budaya islam, yaitu seni budaya yang tidak terlepas dari ajaran dan nilai-nilai agama islam. Oleh karena itu seni sangatlah menarik perhatian yang sangat serius dalam ajaran agama islam.

Agama islam melalui Al Qur'an sendiri sangatlah menghargai seni, melalui Al-qur'an yang sebagai pedoman hidup manusia untuk mengenal Allah dan secara tidak langsung mengajak memandang seluruh jagad raya yang diciptakan oleh-Nya dengan indah. Seni digambarkan seperti kita melihat dunia ini yang begitu indah dari segi wujud fitrahnya. Seperti itulah islam menyenagi keindahan dimana keindahan itu sendiri merupakan makna dari seni.

Seni kaligrafi merupakan seni lukis yang mengekspresikan keindahan kalam Allah. Tak lepas dari itu, seni juga harus sesuai dengan syariat-syariat Islam. Bagaimana hukumnya di dalam Islam harus diketahui demi diterimanya segala amal perbuatan kita di hadapan Allah.

Selain untuk mengekspresikan keindahan kalam Allah, proses pembuatan karya seni kaligrafi ini sangat membantu manusia untuk membentuk karakter Islam yang sebenarnya. Dengan detail-detail kaligrafi yang harus diperhatikan, khat yang beragam dengan kesulitan yang berbeda, dan kaidah penulisan atau tata bahasa yang harus diperhatikan agar tidak terjadi salah pengertian memaksa pelukis untuk senantiasa sabar, tekun, gigih, dan disiplin. Tak hanya itu, karakter-karakter lain juga akan terbentuk dengan seiring waktu mempelajari kaligrafi.

Sesuai dengan tujuan utama dari Pendidikan Agama Islam yang membentuk karakter Islam di dalam diri peserta didik, bagaimanan peran dari seni kaligrafi dalam proses pembelajaran Pendidikan Agama Islam akan dibahas dalam artikel ini. 


\section{METODE PENELITIAN}

Kajian ini adalah penelitian kajian Pustaka yang dilakukan dengan mengumpulkan data, membaca-baca serta mengambil data dari sumber berupa buku dan laporan ilmiah yang berkaitan berkaitan dengan objek penelitian ini, untuk menganalisis dan mendeskripsiksn urgensi dari seni kaligrafi dalam pendidikan Islam. Metode pengumpulan data diarahkan pada pengumpulan refrensi- refrensi buku teks yang ditulis rapi dalam format softfile, maupun jurnal penelitian terdahulu yang sesuai dengan topik dari kajian ini.

\section{HASIL DAN PEMBAHASAN}

Al Qur'an sebagai kalam Allah yang isi dan kemurniannya tidak dapat diragukan lagi. Apalagi bagi seorang muslim, Al Quran tidak hanya dibaca saja melainkan isi kandungan serta makna juga harus dipelajari serta diamalkan baik untuk diri sendiri maupun kepada orang lain. Kalam Allah yang indah dapat dinikmati melalui karya seni yang dinamakan kaligrafi.

Kaligrafi berasal dari bahasa latin dan terdiri dari dua suku kata yaitu kalios (calios) artinya keindahan, dan graph (graph) artinya gambar atau tulisan. ${ }^{5}$ Dalam Bahasa Arab, kaligrafi disebut khat, yang berarti "dasar garis", "coretan pena" atau "tulisan tangan". Dalam bentuk kata kerjanya adalah khatta yang berarti kutaba (menulis) atau rasama (menggmabar).

Bahasa Arab menggunakan kata "khat" (tulisan atau baris) sebagai kaligrafi, yang ditampilkan dalam tulisan yang sangat indah (al-Kitabbah al-jamilah atau al-khat al-jamil). Dari segi terminologi, Syekh Siamsuddin Afkani (ahli kaligrafi) dengan jelas menemukan dalam bukunya "irshad al qasid" bahwa Khat merupakan bentuk satu huruf, letaknya dan bagaimana menyusunnya Sesuatu yang dirangkai menjadi bentuk tertulis atau tertulis dalam bentuk tertulis. ${ }^{6}$

Kaligrafi merupakan suatu kalam Allah yang ditulis atau digambarkan oleh para ahli dengan sentuhan seni. Mengutip D. sirojuddin AR, secara terminologis

${ }^{5}$ Rispul, “Kaligrafi Arab Sebagai Karya Seni," Jurnal Kajian Seni Budaya Islam Vol 1 (June 2012): 12. ${ }^{6}$ Laily Fitriani, "Seni Kaligrafi : Peran Dan Konstribusinya Terhadap Peradaban Islam," El Harakah Vol 13 No 1 (2011): 4. 
Kaligrafi adalah ilmu yang memperkenalkan bentuk huruf tunggal, lokasinya, dan cara gabungannya menjadi teks terstruktur. Atau apapun yang tertulis secara online, bagaimana menulisnya, menentukan apa yang tidak perlu ditulis, mengubah ejaan yang perlu diubah dan menentukan bagaimana mengubahnya. ${ }^{7} \mathrm{Hal}$ yang mengagumkan dari seni kaligrafi bawasannya dalam hal membaca dan menulis adalah perintah dari Allah saat nabi Muhammad saat menerima wahyu pertama kali saat beliau di gua hira. Maka kisah tersebut tertulis pada surat al- alaq 1-5.

Kaligrafi yang menggunakan kaidah khat yang umumnya digunakan ada : khat Kufi, Nashk, Thuluth, Diwani. Dalam penulisannya harus sesuai dengan kaidahkaidahnya. Yaitu kaidah tata cara menulis huruf Arab yang betul agar tulisan dan posisinya sesuai dengan makna yang terkandung. Akan fatal apabila terjadi kesalahan dalam menulis karena peletakan titik saja dapat mengubah makna, bisa jadi kata yang buruk untuk objek yang buruk menjadi baik karena kesalahan kecil saja. Selain itu juga memperhatikan tata cara penulisan sesuai ketetapan-ketetapan yang berlaku dalam macam-macam jenis khat.

Maka, kaligrafi merupakan tulisan indah yang ditulis dengan kaidah-kaidah penulisan dalam hal ini tulisan arab dalam kalam Allah, al Quran, agar tidak mengubah makna dari kalam-Nya.

\section{Hukum seni rupa dalam islam}

Dalam kehidupannya, manusia hidup di dunia ini, diatur seperti ini oleh pencipta. Antara yang di perbolehkan dan yang tidak di perbolehkan untuk dilakukan. Hukum Seni Rupa dalam Islam mengalami banyak perbedaan pandangan hukum dikalangan para ulama.

Muhammadiyah sendiri, melalui Majelis Tarjih telah mengkompromikan beberapa dari argumen yang tampaknya kontradiktif ini. Hasilnya adalah sebagai "Himpunan Putusan Tarjih". Seperti yang dijelaskan di halaman 281 menyatakan: Hukum berputar disekitar gambar "illat (alasan)" (dalam hal ini juga termasuk gambar dan arca), ada 3 jenis:

1. Untuk disembah, hukumnya haram berdasarkan nash.

7 Fitriani, 12. 
2. Untuk sarana pengajaran hukumnya mubah.

3. Untuk perhiasan ada dua macam: pertama, tidak dikhawatirkan mendatangkan fitnah, hukumnya mubah; kedua, mendatangkan fitnah ada dua macam: yang pertama, jika fitnah itu kepada maksiat hukumnya makruh, dan jika fitnah itu kepada musyrik hukumnya haram. ${ }^{8}$

Dari penjelasan di atas, perlu kami jelaskan dua istilah yang menurut kami penting, yaitu fitnah dan maksiat. Fitnah dalam bahasa Arab memiliki banyak arti. Bahkan dalam kamus Lisanul-Arab Ibn Mandzur, kata fitnah memiliki arti yang beragam, dari yang paling hina (seperti memalukan) sampai yang paling berat (seperti bidah dan kufur). ${ }^{9}$ Kata kedua yaitu maksiat, dalam bahasa ini kata asusila merupakan lawan kata dari ketaatan dan memiliki banyak arti, termasuk ketidaktaatan dan kesalahan. ${ }^{10}$

Agar tidak terjadi kesalah pahaman, penting untuk kita menambahkan catatan bahwa fitnah dan perilaku asusila yang mengarah pada hukum makhruh tersebut di atas hanya berarti fitnah dan perilaku tidak bermoral, yang artinya terang dianggap sebagai kesalahan, seperti sarkasme tokoh nasional $\mathrm{Yu}$ menertawakannya. Namun jika maksiat itu kebalikan dari ketaatan, itu perbuatan ketidaktaatan, maka jelas hukumnya haram, misalnya membuat lukisan cabul bisa membuat orang yang melihatnya dan menciptakan dewa memiliki nafsu erotis untuk disembah.

Namun perlu diperhatikan bahwa perbuatan salah yang terus menerus juga dapat mengakibatkan perilaku asusila yang serius dan menjadi kejahatan besar, oleh karena itu, meskipun undang-undang dikatakan tidak benar, sebaiknya hindari tindakan tersebut sebisa mungkin.

Keputusan mengenai hukum menggambar diambil berdasarkan beberapa pertimbangan:

8 Tim Majelis Tarjih dan Tajdid Pimpinan Pusat Muhammadiyah, Tanya Jawab Agama V Yogyakarta: Suara Muhammadiyah, n.d.), 224.

9 Ibn Manzhur, Kamus Komprehensif Arab: LISANUL ARAB, 9 Jilid Lengkap. (Dar Al Hadits, n.d.), 317-18.

10 Manzhur, 293-95. 
Pertama, masalah seni lukis dan seni pahat dapat digolongkan sebagai masalah hukum ma'qulul-ma'na, yaitu masalah hukum syar'i yang logika hukumnya dapat dipahami melalui penalaran rasional.

Kedua, dalam perjuangan Nabi Muhammad SAW memberantas penyembahan berhala dan menjunjung tinggi ajaran Tauhid yang murni, kita bisa melihat larangan pembuatan arca dan gambar makhluk. Jika pembuatan arca dan gambar tidak dihilangkan maka akan terjadi kehancuran akidah baru. Pada saat yang sama, jika tidak ada rasa takut merusak keimanan, maka tidak ada larangan. Sama seperti boneka anak-anak. Hal ini juga dapat dipahami dari alasan mengapa Nabi Muhammad SAW memerintahkan penghapusan tabir gambar, karena dia membuatnya meninggalkan Allah, mengingatkan dunia, dan mengganggu shalatnya yang khusyuk. Jika semua alasan ini tidak ada, maka tidak ada larangan.

Ketiga, di zaman modern ini, arca dan gambar makhluk hidup kebanyakan tidak digunakan untuk beribadah, dan tampaknya tidak ada umat Islam yang menyembah patung. Di sisi lain, arca dan gambar memiliki banyak kegunaan, yang tidak ada pada zaman para nabi, misalnya untuk mengajar, membuat peristiwa sejarah seperti patung piramida biologis menjadi permanen.

Keempat, dalam al-Qur'an, kritik terhadap gambar adalah karena disembah dan dianggap inkarnasi Tuhan. Pada saat yang sama, arca yang dibuat oleh Nabi Sulaiman belum dikritik karena tidak untuk tujuan dan tidak ada hubungannya dengan ibadah. ${ }^{11}$

\section{Urgensi seni kaligrafi dalam Pendidikan agama islam}

Secara kaedah bahasa Indonesia dapatlah dipahami bahwa Pendidikan Islam adalah upaya manusia untuk mengubah sikap dan perilaku seseorang atau suatu kelompok melalui pengajaran atau pelatihan dalam kehidupan, oleh karena itu dalam kehidupan sesuai dengan ajaran yang sesuai dengan ajaran Islam di bawah didikan Nabi Muhammad SAW. ${ }^{12}$ Dari pengertian tersebut, pada intinya adalah proses pendidikan agama Islam untuk mengubah tingkah laku manusia agar menjadi

11 Tim Majelis Tarjih dan Tajdid Pimpinan Pusat Muhammadiyah, Tanya Jawab Agama V, 227-28.

${ }^{12}$ Halid Hanafi, La Adu, and Zainuddin, Ilmu Pendidikan Islam (Yogyakarta: Deepublish, 2018), 36. 
hamba yang taat pada ajaran Islam khususnya melalui proses pengajaran. Pengajaran disini yaitu proses pembelajaran dari pendidik kepada peserta didik.

Sedangkan menurut Armai Arief mengemukakan bahwa Pendidikan Islam adalah proses menumbuhkan potensi kreatif siswa, bertujuan untuk mewujudkan manusia yang beriman dan bertakwa kepada Yang Maha Kuasa, cerdas, terampil, memiliki etika profesi yang tinggi, berakhlak mulia, mandiri dan bertanggung jawab terhadap diri sendiri, bangsa, negara dan agama. ${ }^{13}$ Untuk mewujudkan tujuan-tujuan tersebut, dapat menggunakan suatu karya seni sebagai media pembelajarannya, termasuk seni kaligrafi.

Selain tuntutan menegakkan syariat Islam, Islam juga sangat menjunjung tinggi seni dan budaya. Seni dan budaya mampu meningkatkan keterampilan, olah rasa, kecerdasan dan karakter-karakter lain sesuai dengan tujuan pendidikan Agama Islam. Olah rasa dapat tumbuh dengan pengalaman keindahan suatu karya seni. Dengan kemampuan berolah rasa, dapat menjadi sumber dari pengendalian diri. Kemurnian tulisan yang indah adalah pertanda kelembutan dan manisnya hati. ${ }^{14}$

Selain itu juga seni juga bisa menjadi sarana untuk meningkatkan kebijaksanaan spiritual. Menurut syekh Abdulhalim Mahmud yang dikutip oleh Asbullah Muslim,bukti terkuat mengenai wujud Tuhan ada pada rasa manusia, bukan akal.

Seni bukan merupakan objek yang menyangkut selera pribadi, akan tetapi menyangkut Keinginan manusia yang lebih tinggi, yaitu keruhanian. Seperti yang diungkapkan oleh Imam Al-Ghazali, pengaruh karya seni terhadap jiwa manusia sangat besar, dan karenanya menentukan apresiasinya terhadap moralitas dan agama. Karena berbagai bentuk kecantikan dapat digunakan sebagai sarana pengalaman religius, menurut cara orang menanggapi keindahan, estetika dalam tradisi Islam dapat dikatakan sebagai jalan spiritual. ${ }^{15}$

Penulisan kaligrafi tidak hanya terkait dengan keterampilan dan keterampilan, tetapi juga terkait dengan penglihatan spiritual. Secara tidak

\footnotetext{
${ }^{13}$ Hanafi, La Adu, and Zainuddin, 46.

14 Abdul Hadi, Hermeneutika Estetika Dan Religiuditas (Jakarta Selatan: Sadra Press, 2016), 262.

15 Hadi, 44.
} 
langsung, menulis kaligrafi merupakan sarana untuk menjaga hati, perkataan, pikiran dan perilaku masyarakat. ${ }^{16}$ Karena dengan menulis, otomatis kitalmembaca ayat yang sedang ditulis tersebut.

Secara garis besar pendidikan merupakan proses pengembangan potensi yang meliputi tiga aspek kehidupan yaitu pandangan hidup, sikap hidup dan keterampilan hidup. ${ }^{17}$ Harus ada keseimbangan antara pengembangan kemampuan otak, hati, dan otot. Jika seni budaya diintegrasikan dalam PAI, maka dapat mengasah perkembangan kemampuan berpikir kritis, mengapresiari hasil, dan mengaplikasikan nilai-nilai seni budaya dalam perilaku nyata.

Seni kaligrafi juga dapat digunakan sebagai media mengajar dalam pembelajaran Bahasa Arab yang juga bagian dari Pendidikan Agama Islam. Penentuan ayat Al-Quran untuk kaligrafi yang sesuai tema pembelajaran dapat menghindari ketidaksesuaian dengan kurikulum. Ketika anak didik mengerjakan sebuah kaligrafi, guru dapat menjelaskan arti kata-kata atau tata bahasa yang terdapat dalam ayat yang sedang dilukis dan siswa dapat mendengarkan. Selain aspek visual terdukung dengan lukisan-lukisan menarik, aspek audio dan kinestetik pun tercakup di dalamnya.

Melaksanakan kegiatan kaligrafi atau daun katha untuk meningkatkan rasa keindahan dan seni sehingga membentuk sikap kreatif, apresiatif dan kritis. Sebagai salah satu cabang seni, kaligrafi berperan dalam memberikan apresiasi dan pengalaman kreatif bagi siswa. Selain itu juga dapat menghasilkan suatu produk benda yang bermanfaat bahkan bernilai jual tinggi.

Kaligrafi juga dapat berperan dalam membentuk kepribadian dan harmoni siswa secara keseluruhan (termasuk logika, moralitas, estetika dan kesenian) untuk menumbuhkan kreativitas, kepekaan terhadap rasa dan perasaan, dan moralitas. ${ }^{18}$ Nilai-nilai karakter seorang muslim dapat tumbuh dengan mempelajari kaligrafi, seperti nilai religiusitas yang ditunjukkan dengan sikap dan perilaku patuh

16 Ananda Rakhmatul Ummah, "Nilai-Nilai Edukasi Dalam Menulis Kaligrafi Arab: Penelitian Di Lembaga Kaligrafi Al-Qur'an (LEMKA) Ciputat” (Jakarta, UIN Syarif Hidayatullah, 2019), 56.

17 Asbullah Muslim, "Urgensi Estetika Dan Budaya Islam Dalam Pendidikan Agama Islam," Palapa: Jurnal Studi Keislaman Dan Ilmu Pendidikan Vol 1 No 1 (Mei 2013): 57.

18 Roisudin, 190. 
melaksanakan ajaram Islam. Selain itu juga jujur, disiplin, kerja keras, sabar, dan kreatif. Contoh yaitu ketika menulis kaligrafi dibutuhkan kesabaran yang tinggi untuk membentuk sempurna tulisan tersebut. Masih banyak manfaat lain dari proses mempelajari dan membuat seni kaligrafi ini, terutama manfaat bagi kecerdasan spiritual dan nilai-nilai personal.

Bahkan nilai-nilai sosial juga tumbuh pada diri seseorang ketika pembelajaran kaligrafi. Nilai- nilai sosial yang tumbuh dalam diri seseorang dalam proses ini diantaranya ialah : meneladani, profesional, patuh atau taat aturan, santun, membawa manfaat, dan menghargai prestasi karya orang lain. ${ }^{19}$ Meneladani demonstrasi dari guru pengajar, mahir dalam berkaligrafi, patuh dan taat pada aturan untuk membentuk kaligrafi yang sesuai kaidah, serta sikap santun dan kebaikan lainnya dalam memaknai hikmah dari ayat yang ditulis. Selain itu juga bermanfaat bagi umat, dan menghargai atau tidak merasa angkuh dengan karya orang lain. Karena mengetahui bahwa selama proses menghasikan karya kaligrafi pastilah tidak mudah.

Jadi apabila seni kaligrafi ini dapat diajarkan dalam pembelajaran pendidikan Agama Islam, tidak hanya aspek keindahan yang didapat oleh peserta didik, namun juga dapat membentuk kepribadian secara menyeluruh. Selain itu aspek spiritual keagamaan peserta didik juga dapat terbentuk, sesuai dengan tujuan dari pendidikan Agama Islam. Secara singkat, kegiatan berkaligrafi dapat mengembangkan hal- hal pokok yaitu rasa, akal, dan iman.

\section{Kesimpulan}

Seni kaligrafi merupakan seni rupa berupa tulisan indah yang disesuaikan kaidah-kaidah khatnya agar tidak terjadi perubahan makna dari ayat yang disampaikan. Hukum seni rupa adalah haram apabila gambar tersebut merupakan gambar untuk disembah atau apabila menimbulkan fitnah dan maksiat. Namun untuk pengajaran hukumnya adalah mubah.

Seni kaligrafi dapat digunakan sebagai materi ataupun bahan ajar untuk proses pembelajaran Pendidikan Agama Islam, karena seni sendiri menyangkut kepada

${ }^{19}$ Ummah, "Nilai-Nilai Edukasi Dalam Menulis Kaligrafi Arab : Penelitian Di Lembaga Kaligrafi AlQur'an (LEMKA) Ciputat,” 60. 
hasrat tertinggi manusia, yaitu keruhanian. Dimana hal ini merupakan tujuan pokok dari proses Pendidikan Agama Islam yaitu iman dan ketauhidan. Selain itu juga dapat membentuk karakter Islami bagi pelukis kaligrafi bahkan nilai- nilai sosial dalam berinteraksi dengan pencipta-Nya maupun sesamanya.

\section{DAFTAR PUSTAKA}

Dedi Nurhadiat. Pendidikan Seni Rupa. Jakarta: Grasindo, 2004.

Fitriani, Laily. "Seni Kaligrafi: Peran Dan Konstribusinya Terhadap Peradaban Islam." El Harakah Vol 13 No 1 (2011).

Hadi, Abdul. Hermenentika Estetika Dan Religinditas. Jakarta Selatan: Sadra Press, 2016.

Hanafi, Halid, La Adu, and Zainuddin. Ilmu Pendidikan Islam. Yogyakarta: Deepublish, 2018.

Jim Supangkat and Rizki A Zaelani. Ikatan Silang Budaya; Seni Serat Biranul Anas. Art Fabrics, 2006.

Manzhur, Ibn. Kamus Komprehensif Arab: LISANUL ARAB, 9 Jilid Lengkap. Dar Al Hadits, n.d.

Muslim, Asbullah. "Urgensi Estetika Dan Budaya Islam Dalam Pendidikan Agama Islam.” Palapa: Jurnal Studi Keislaman Dan Ilmu Pendidikan Vol 1 No 1 (Mei 2013).

Rispul. "Kaligrafi Arab Sebagai Karya Seni." Jurnal Kajian Seni Budaya Islam Vol 1 (June 2012).

Roisudin, Ayi Sisma. "Menumbuhkan Nilai-Nilai Karakter Melalui Pendidikan Khat Al-'Arabiy: Studi Kasus Di Sekolah Kaligrafi Al-Quran (SAKAL) Pondok Pesantren Mamba'ul Ma'arif Denanyar Jombang." Didaktika Religia Vol 3 No 1 (2015).

Syafril and Zelhendri Zen. Dasar-Dasar Ilmu Pendidikan. Depok: Kencana, 2017.

Tim Majelis Tarjih dan Tajdid Pimpinan Pusat Muhammadiyah. Tanya Jawab Agama $V$. Yogyakarta: Suara Muhammadiyah, n.d.

Ummah, Ananda Rakhmatul. "Nilai-Nilai Edukasi Dalam Menulis Kaligrafi Arab: Penelitian Di Lembaga Kaligrafi Al-Qur'an (LEMKA) Ciputat." UIN Syarif Hidayatullah, 2019.

Yani Mulyani and Juliska Gracina. Kemampuan Fisik, Seni, Dan Manajemen Diri. Jakarta: Kelompok Gramedia, 2007. 